\title{
Multiple parameters anomalies for verifying the geosystem spheres coupling effect: a case study of the 2010 Ms7.1 Yushu earthquake in China
}

\author{
Shuo Zheng ${ }^{1}$, Lixin X. Wu ${ }^{2,1, *}$, Kai Qin ${ }^{2}$ \\ ${ }^{1}$ Academy of Disaster Reduction \& Emergency Management, Beijing Normal University, Beijing, China \\ ${ }^{2}$ School of Environment Science and Spatial Informatics, China University of Mining and Technology, Xuzhou, China
}

\author{
Article history \\ Received February 19, 2014; accepted July 2, 2014. \\ Subject classification: \\ Solid Earth, Seismology, Surveys, measurements and monitoring, Earthquake interactions and probability.
}

\begin{abstract}
In the research of earthquake anomaly recognition, the coupling effect of multiple geosystem spheres can be expected to reasonably interpretating the correlation between various anomalous signals before strong earthquake. Specially, the development of the Lithosphere-Atmosphere-Ionosphere (LAI) coupling model has been accepted as verified by some experimental, thermal and electromagnetic data. However, quasi-synchronous anomalies of the multiple parameters, including thermal, radon and electromagnetic data, have not been reported in a single event case for verifying the geosystem spheres coupling effect. In this paper, we firstly summarized the reported studies on the power spectrum density (PSD) in the ELF/VLF band and radon data recorded from Guza seismic station. Then, historical surface latent heat flux (SLHF) data from the NCEP/NCAR Reanalysis Project was employed for investigating anomalous change in a month before the April 14, 2010, Ms7.1 Yushu earthquake which is one of the typical intra-continental earthquakes in Tibet Plateau. The results from spatial and temporal analysis revealed that anomalous fields of PSD and SLHF data were located close to the epicenter and the ends of some active faults at Bayan Har Block and all anomalous dates converged between April 8 and 11 (6 to 3 days before the Yushu earthquake). Therefore, we suggest that the anomalies of multiple parameters before the main shock are related with the Yushu earthquake. This paper could give an ideal case study to verify the geosystem spheres coupling effect happened in a single event.
\end{abstract}

\section{Introduction}

The great earthquake anomaly has become naturally a hot topic due to its indicative information of earthquake prediction. A larger number of studies have suggested that anomalous variation of thermal signals existed before many medium-to-large ( $\mathrm{M}>5.5)$ earthquakes, such as thermal infrared radiation (TIR) [Qiang et al. 1991, Tronin 1996, Tronin et al. 2002, Saraf and Choudhury 2004, Tronin 2006, Pulinets and Dunajecka
2007], surface latent heat flux (SLHF) [Dey and Singh 2003, Qin et al. 2009, 2011, 2012], outgoing longwave radiation (OLR) [Ouzounov et al. 2007], and microwave radiation [Tadashi and Takashi 2009]. Besides the thermal parameters in atmosphere, total electron concentration (TEC) in ionosphere [Pulinets et al. 2006, Zhao et al. 2008, Zhang et al. 2009, Zeren et al. 2012] and some types of gaseous components in lithosphere [Singh et al. 2010] were also reported in recent years. Multiple parameters anomalies show various spatiotemporal features for scientific understanding with seismic knowledge. To explain a correlation between these anomalies and local tectonic activity, some hypotheses, such as local greenhouse effect [Ouzounov et al. 2006], transient electric field [Liperovsky et al. 2005, 2008a, 2008b], positive hole (P-hole) effect [Freund 2011] and Earth degassing and hence resulting in the greenhouse effect [Qiang et al. 1995, Tronin et al. 2002], have been presented. Further, a unified Lithosphere-AtmosphereIonosphere (LAI) coupling effect was proposed to understand the inherent correlations between different parameters, or on the geological correlations with tectonic structures [Pulinets et al. 2000, Liperovsky et al. 2008a, Pulinets and Ozounov 2011, Pulinets 2012, Pulinets and Davidenko 2014]. Moreover, Wu et al. further emphasize especially the influence of Coversphere (including planet Earth's surface sand, soil, vegetation, water body, etc.) which is quite different from the underground rock in lithosphere to satellite remote sensing and to thermal anomaly mechanism [Wu et al. 2012]. The geo-spheres coupling effect makes the multiple parameters earthquake anomaly a universal significance and general acceptance in scientific community. As one of pore gases naturally occurring in the crust 


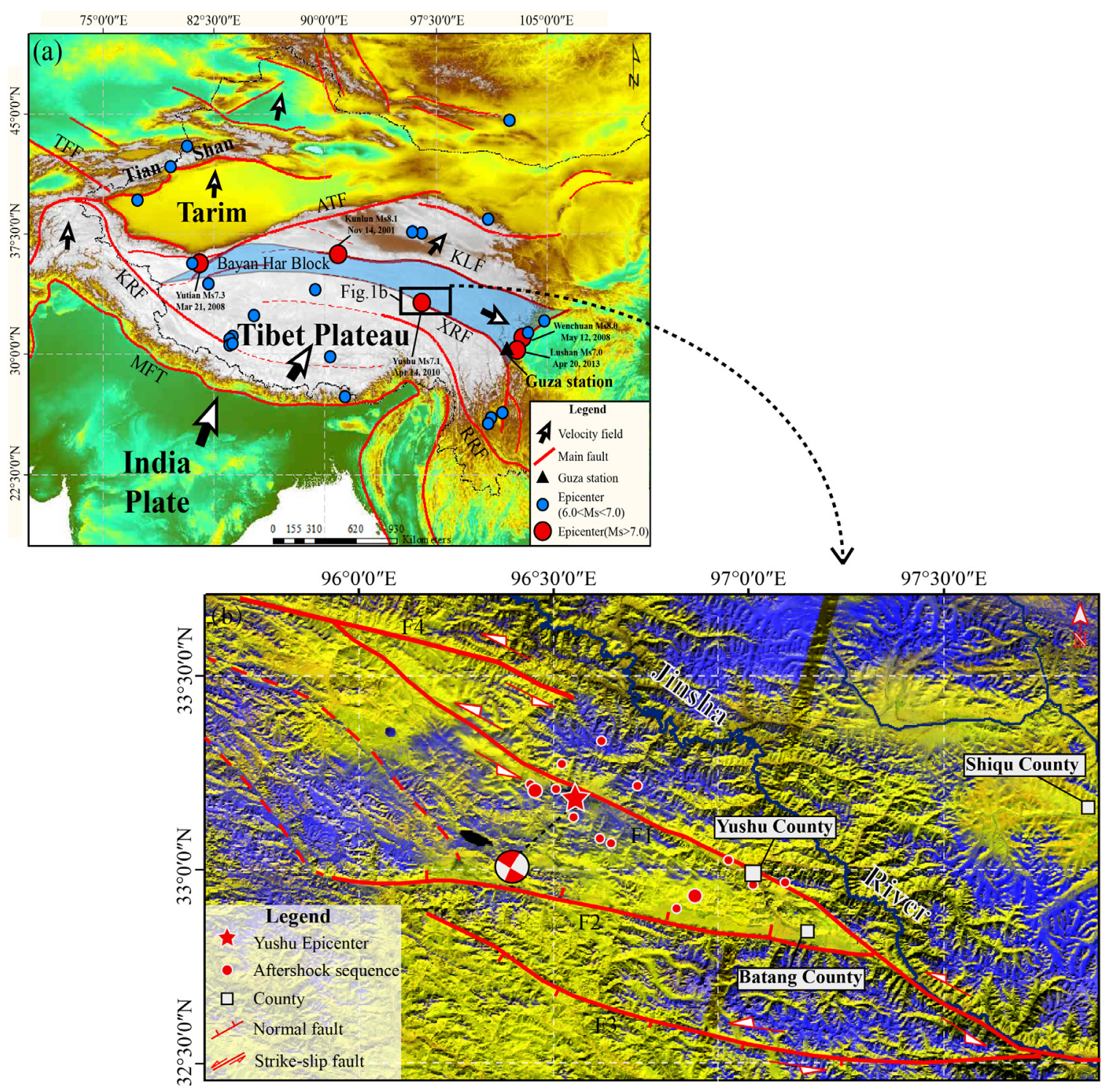

Figure 1. Simplified active tectonic map of the Tibetan Plateau and surrounding region (a) and the Ganzi-Yushu region overlapped on a false color image from Landsat ETM+ (b). Major fault systems are: ATF-Altyn Tagh fault, KLF-Kunlun fault, KRF-Karakoram fault, MFT-Main frontal fault, RRF-Red River fault, XRF-Xianshuihe fault.

rock, radon plays the important role in the spheres coupling process because the increased radon with high radioactivity in seismically active areas before earthquakes is the primary source of air ionization [Pulinets and Ozounov 2011]. After the regular gas molecules are activated by radon ionization to generate gas ions in the air, the ions hydration happen as a consequent reaction. The concentration of hydrated particles will provide an essential contribution in thermal variation (including SLHF, etc.). Meanwhile, regional electric field generation as a result of charge separation during the air motion of hydrated particles. The electric field continually penetrates to upper layer and finally causes the ionospheric perturbation. However, few papers have verified the coupling effect by a single earthquake case with quasi-synchronous anomalies of multi-parameters (the gas radon, thermal and electromagnetic data especially) in different spheres so far.
The Tibetan plateau, the highest and largest plateau in the world, is a region of active deformation and seismicity by the result of the collision of the Indian plate with Asia [Fu et al. 2011]. Since the 21st century, there were four strong intra-continental earthquakes with magnitude $\mathrm{Ms}>7.0$ in the Tibetan plateau, including Ms8.1 Kunlun earthquake on November 14, 2001, Ms7.3 Yutian earthquake on March 21, 2008, Ms8.0 Wenchuan earthquake on May 12, 2008, Ms7.1 Yushu earthquake on April 14, 2010, and Ms7.0 Lushan earthquake on April 20, 2013, respectively, and all of earthquakes coincidently happened on the boundary active fault around the Bayan Har block (Figure 1a). The Yushu earthquake was on the northwestern segment of the NWW-SEE oriented Ganzi-Yushu fault which is a zone of active left-lateral strike-slip faulting in the late Quaternary and merges in the southeast with the leftlateral slip Xianshuihe Fault (XSHF) system, finally ter- 

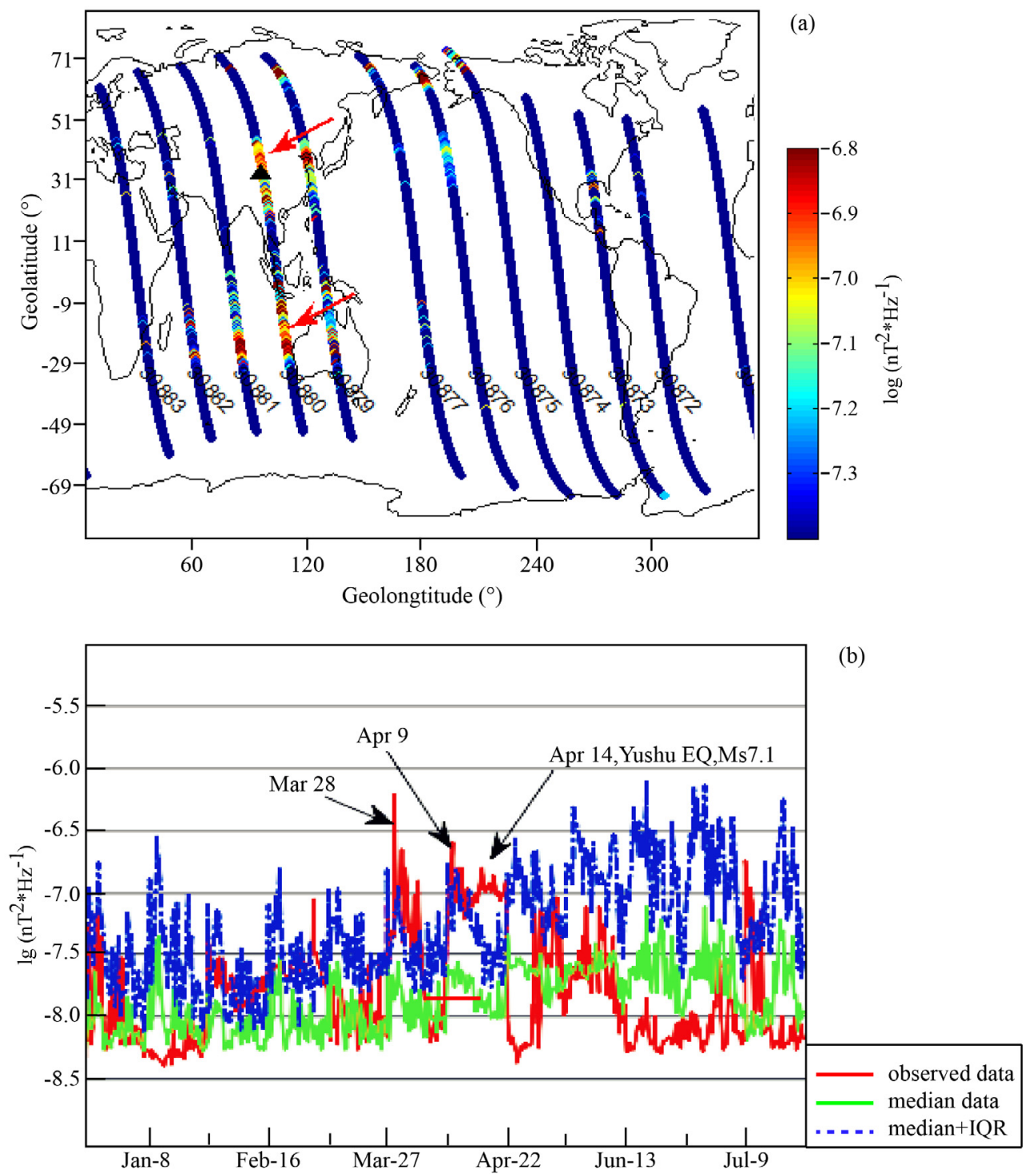

Figure 2. The global distribution of PSD of magnetic field at $410 \mathrm{~Hz}$ recorded by IMSC on April 9, 2010 (b), the black triangle represents the epicenter, and the two red arrows indicate the enhanced PSD locations. And time series of the PSDs data of magnetic field at $410 \mathrm{~Hz}$ from January 8 to July 9, 2010 (b), the red, green, and blue curves denote the observed PSD value, the moving median, and the median data plus IQR, respectively [Zeren et al. 2012].

minates against the Dangjiang fault to the northwest [Wang et al. 2008, Chen et al. 2010, Rao et al. 2011]. The epicenter $\left(96.56^{\circ} \mathrm{E}, 33.22^{\circ} \mathrm{N}\right)$ is located in approximately $44 \mathrm{~km}$ from the Yushu county, and two strong aftershock events were recorded with relatively large magnitudes (Ms6.3 and Ms5.7) near the main shock region [Shan et al. 2011]. From the perspective of the geometry characteristics of faulting tectonics, the Yushu region is just located at the rhomb-shaped stepover of Ganzi-Yushu fault zone where the earthquake prone (Figure 1b) [Sun et al. 2010, Wang et al. 2013].

After the Yushu earthquake, some electromagnetic and radon precursor anomalies related to this earthquake were reported [Li et al. 2011, Zeren et al. 2012]. Whether there were also the anomalous changes of thermal parameters associated with this event? If so, whether abnormal thermal anomalies were quasi-syn- chronous with electromagnetic and radon anomalies? To answer the questions, we firstly summarized the reported ionospheric perturbation and radon anomalies in this paper. Then, the spatio-temporal features of SLHF data were analyzed. Finally, combining with the alternative anomalous time of multiple parameters, we confirm the anomalies of multiple parameters related to the Yushu earthquake based on the spatial geo-consistency and temporal quasi-synchronism [Wu et al. 2006a, 2012, Qin et al. 2012] and try to give a comprehensive case study with the anomalous variations for verifying geosystem spheres coupling effect.

\section{Reported electromagnetic perturbation and radon anomaly}

As far as we know, ionospheric electromagnetic perturbation is an anomaly phenomenon of the outer- 


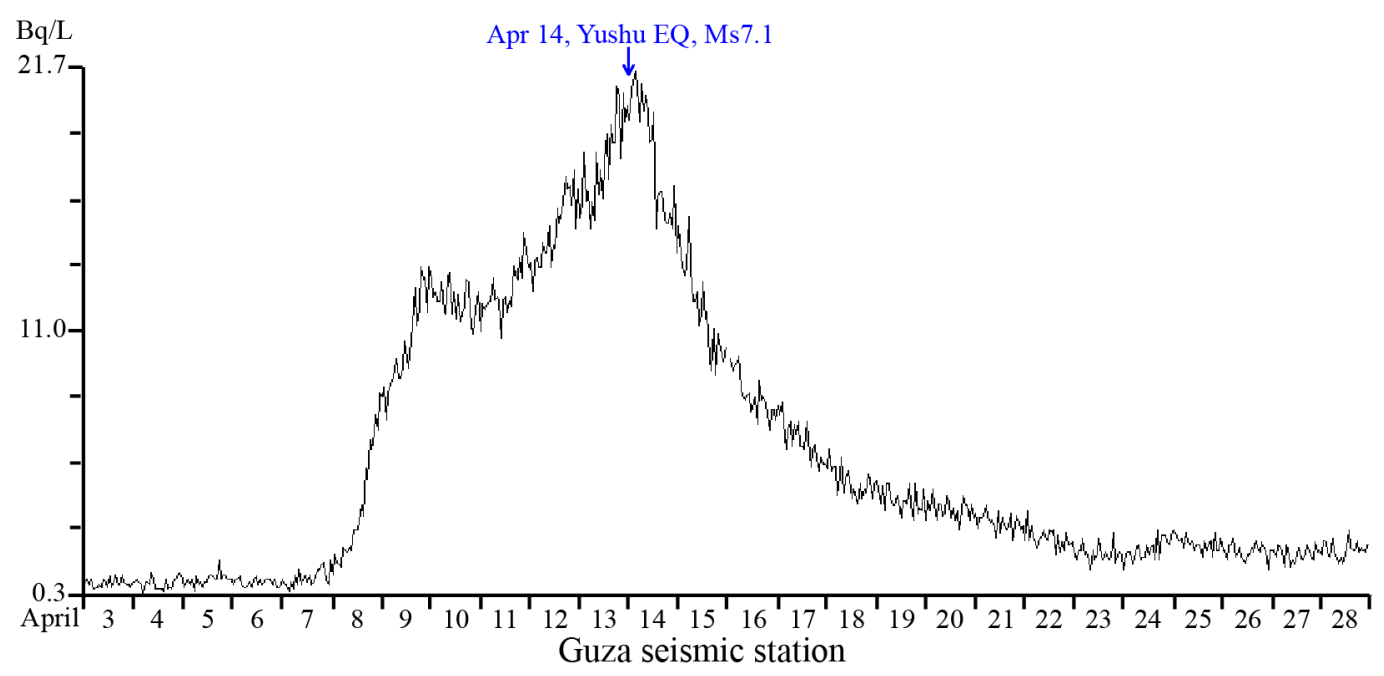

Figure 3. The gas radon anomaly curve before Yushu earthquake at Guza seismic station, and the locations of this station shows in Figure 1a, the black triangle [Li et al. 2011].

most layer of the earth and also the final effect to the earthquake in the geosystem spheres coupling process. Relatively, the anomalous variation of radon under the ground is generally regarded as a kind of initial response induced by active fault motion in lithosphere prior to the earthquake. Two types of anomalies before the Yushu earthquake have been reported. Zeren et al. have used the PSD (the power spectrum density) data of magnetic field in the ELF/VLF range $(370-8,798 \mathrm{~Hz})$ recorded by IMSC (Instrument of Magnetic Search Coil) onboard the DEMETER satellite for studying ionospheric variation from January 1st to April 30, 2010, in a $2,000 \mathrm{~km}$ area around the epicenter [Zeren et al. 2012]. The strongest PSDs at $410 \mathrm{~Hz}$ perturbations occurred during the night on April 9, 4 days before Yushu earthquake. Figure 2a shows that the largest magnetic field in the orbit 30,880_up located at the top of the epicenter in the northern hemisphere. The PSD values were larger than $10^{-7} \mathrm{nT}^{2} / \mathrm{Hz}$. The researchers further investigated the time series of PSD using revisited orbits above the epicenter area and found an increase of the PSD value at $410 \mathrm{~Hz}$ at 17 and 4 days before this earthquake based on an inter-quartile-ranges (IQR) method (Figure 2b). After checking that the solar and geomagnetic activities were quiet at the same period, the PSD spatio-temporal anomalies can be considered related to the Yushu earthquake.

On the other hand, Li et.al have systematically analyzed and summarized instruments' interference and the daily, monthly and annual dynamic variation of the gas radon data from Guza seismic station (The black triangle indicates the location in Figure 1a), and finally identified the abnormal fluctuation of radon at a few days before Yushu earthquake [Li et al. 2011]. In Figure 3 , the main feature was that the two peaks of radon between April 8 and 14. According to the author's survey, after the low stability of nearly 4 months, the measured value suddenly began to rise on April 8. The first peak was approximately $13.6 \mathrm{~Bq} / \mathrm{L}$ on April 9. Then radon concentration was increasing day by day and reached the highest value with about $21.7 \mathrm{~Bq} / \mathrm{L}$ before impending earthquake. In addition, the similar change characteristics of radon concentration were also observed before Ms8.0 Wenchuan earthquake [Li et al. 2011]. It shows that the gas radon at Guza seismic station has a good earthquake-responding ability.

Therefore, both the radon anomaly in lithosphere and the PSDs electromagnetic perturbation in ionosphere do existed prior to the Yushu earthquake, which can provide the strong proof of different geosystem spheres coupling effect.

\section{SLHF data analysis}

\subsection{Data and method}

Thermal parameters for investigating earthquake precursor generally include land surface temperature, air temperature, SLHF and outgoing longwave radiation (OLR). From research results in the past decade, SLHF is regarded as the optimal one in thermal parameters [Dey and Singh 2003, Qin et al. 2009, 2011, 2012]. Here, the daily SLHF data of 1979-2010 are selected from the NCEP/NCAR (the National Centers for Environmental Prediction and the National Center for Atmospheric Research) Reanalysis Project, USA, with global spatial coverage in T62 Gaussian grid with $192 \times 94$ points (192 lines of longitude from $0^{\circ} \mathrm{E}$ $358.125^{\circ} \mathrm{E}, 94$ lines of latitude from $88.542^{\circ} \mathrm{N}$ to $88.542^{\circ} \mathrm{S}$, with a resolution of $1.9^{\circ}$ longitude by $1.9^{\circ}$ latitude). This project is using a state-of-the-art analysis/forecast system to achieve data assimilation using past data of multi-source observations including land 

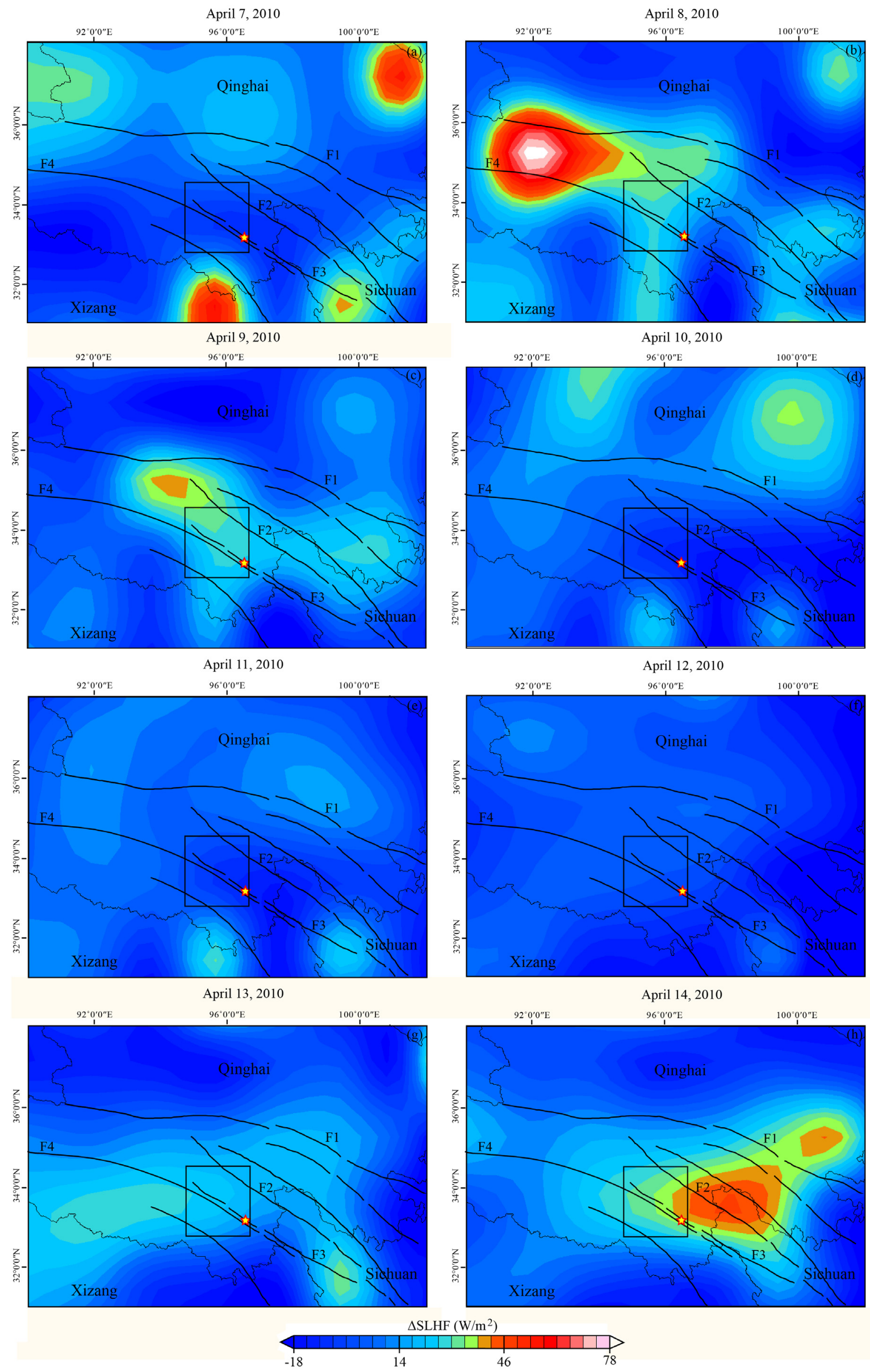

Figure 4. The SLHF difference images of the daily mean in the Yushu region from April 7 to 14, 2010. The yellow stars indicate the epicenter. The black rectangular boxes indicate the epicenter pixel $\left(33.36^{\circ} \mathrm{N}, 95.6^{\circ} \mathrm{E}\right)$. 
surface station, tethered balloon, ship, aircraft and satellite from 1948 to the present.

Considering the seasons, terrain, weather and latitude factors, we get the spatial imaging of the changed SLHF $(\triangle S L H)$ by subtracting the daily SLHF from the multi-years means which represents a normal background:

$$
\Delta S L H=S L H F_{e q} \mid-\frac{1}{n} \sum_{i=1}^{n} S L H F_{i}
$$

Here, $S L H F_{e q}$ is the daily mean SLHF of 2010; $S L H F_{i}$ is the corresponding daily mean SLHF for 19802009.

A statistical method based on the mean $(\mu)$ and standard deviation $(\sigma)$ within the corresponding period of non-earthquake years was used on the single pixel in the vicinity of the epicenter for time series change analysis of SLHF dataset. The threshold, $\mu \pm 2 \sigma$, was defined as abnormal threshold.

\subsection{Spatio-temporal features}

The spatial distribution of $\Delta S L H$ over a large region $\left(90^{\circ}-102^{\circ} \mathrm{E}, 31^{\circ}-38^{\circ} \mathrm{N}\right)$ was calculated and mapped in the period from February 12 to April 14, 2010. The $\triangle$ SLH images of a week before this earthquake are shown in Figure 4. Firstly, both of the spotshaped fields were observed at the bottom and the top right corner of the image on April 7. It is worth to note that a week anomaly was at the end of the Yushu fault (F3). Besides, the Bayan Har Block region with upper and lower boundary as F1 and F4 was "peaceful", and the difference values were less than 14 (Figure 4a). However, a large and strong $\triangle S L H$ anomaly with the central value as high as about $60 \mathrm{~W} / \mathrm{m}^{2}$ appeared suddenly at the northwest of the epicenter on April 8 and covered the western margin of F1 and F4 (Figure 4b). Then, this anomalous field diminished significantly with a little of eastward migration to near the western ends of F3 and F2 on April 9 (Figure 4c). In the subsequent three days (April 10 to 12), pre-existing anomalous fields nearly disappeared (Figure 4d-f). After in a larger area of light SLH variation with the mean value of approximately $40 \mathrm{~W} / \mathrm{m}^{2}$ appeared again and mainly distributed in the bottom of $\mathrm{F} 4$ and the eastern end of F3 (Figure 4g), an irregular polygon anomaly field with
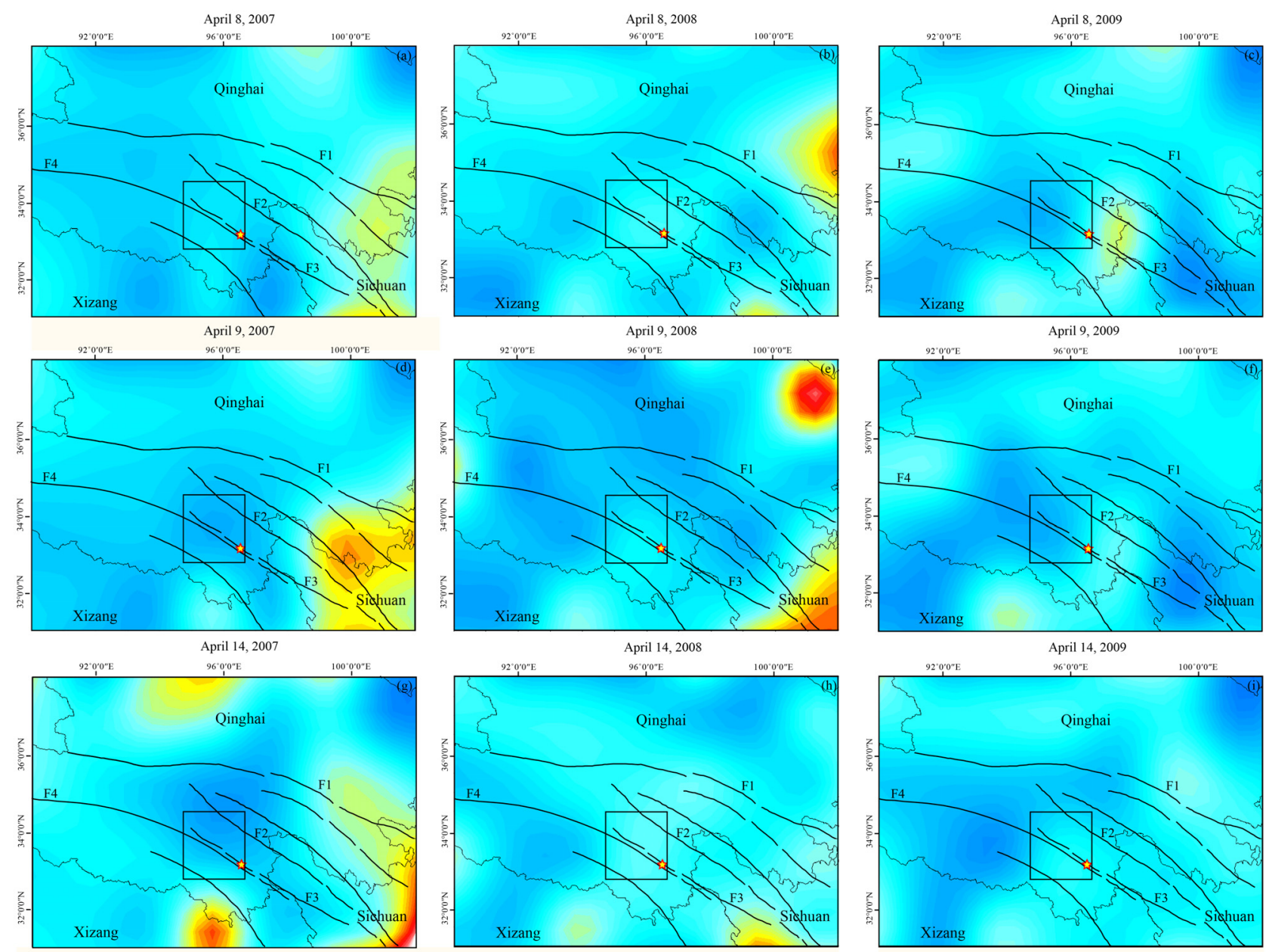

$\operatorname{SLHF}\left(\mathrm{W} / \mathrm{m}^{2}\right)$

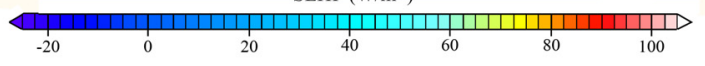

Figure 5. The SLHF images of the daily mean in the Yushu region on April 8, 9 and 14 in the non-earthquake years from 2007 to 2009. 
highest value of $50 \mathrm{~W} / \mathrm{m}^{2}$ is revealed in the northeast near the epicenter on the day of shocking. This anomalous area covered several major faults at the eastern side of the Longmenshan fault zone, including F1, F2 and F3 (Figure 4h).

The analysis of the spatial patterns of SLHF anomalies shows that the spatial abnormal evolution was characterized by intermittent migration in special tectonic parts, and $\triangle S L H$ values reached to local high level on April 8, 9, 13 and 14. Wu et al. have observed the TIR intermittent migration phenomenon in the experiment of loaded rock in the condition of biaxial stress and frictional slide [Wu et al. 2000]. And likewise, the Ganzi-Yushu fault zone can be regarded as the frictional slip zone of loaded rock in a larger scale. So the SLHF spatial feature, which the anomalous field intermittently appeared in different position within the block, possibly indicates stress adjustment and transfer of the seismogenic system. The SLHF abnormal fields were obviously under the control of relevant tectonic faults in Bayan Har Block. To further investigate SLHF spatial anomalies related to the Yushu earthquake, data from the corresponding period in the non-earthquake years from 2007 to 2009 were chosen for comparison (Figure 5). The most remarkable feature is that the SLHF spatial distribution is in a normal state on the same dates of three non-earthquake years, but no anomalies similar to these that appeared obviously on April 8, 9 and 14, 2010, were seen. The normal range of SLHF values is between 20 and $60 \mathrm{~W} / \mathrm{m}^{2}$. In addition, we found that the local anomalous fields at the northeast corner and the bottom of the images in 2010 also appeared in 2007 and 2008 (Figure $5 \mathrm{e}$ and 5g). It indicates that these spatial anomalies might be mainly controlled by geographic and meteorological factors and excluded for that associated with the Yushu earthquake. Hence, the SLHF anomalous distribution in Bayan Har Block just was observed in 2010 and very likely related to the Yushu earthquake.

The possible SLHF anomalies caused by the earthquake should be confined to the vicinity of the epicenter and the relative active faults. Here, we chose the epicenter pixel (at $33.36^{\circ} \mathrm{N}, 95.6^{\circ} \mathrm{E}$, the black rectangular boxes in Figure 4) for the analysis of SLHF time series processing. Figure 6 shows that the SLHF daily variation curve on the epicenter pixel has a very prominent fluctuation one month before Yushu earthquake (red line). The SLHFs sustained at a relative low intensity from March 14 to April 7. After this stable period of about three weeks, the curve soared on April 8, having a peak value of $68.2 \mathrm{~W} / \mathrm{m}^{2}$ and a high value of 67 $\mathrm{W} / \mathrm{m}^{2}$ can be seen on the next day. Then, the curve restored to the low level again between April 10 and 12 . Subsequently, two abnormal positive SLHF data appeared in two days before the earthquake, and the maximum was $74 \mathrm{~W} / \mathrm{m}^{2}$ on the day of main shock. What is more important is that all of observed SLHF peaks obviously exceed the threshold $\mu \pm 2 \sigma$ as abnormal upper threshold in the corresponding period of nonshock years (blue zone). In addition, most of SLHF daily value in 2010 were a little less than the average of non-shock years except for a few data with slightly larger than the average, which reveal the normal state of pre-earthquake SLHF variation. Therefore, we can

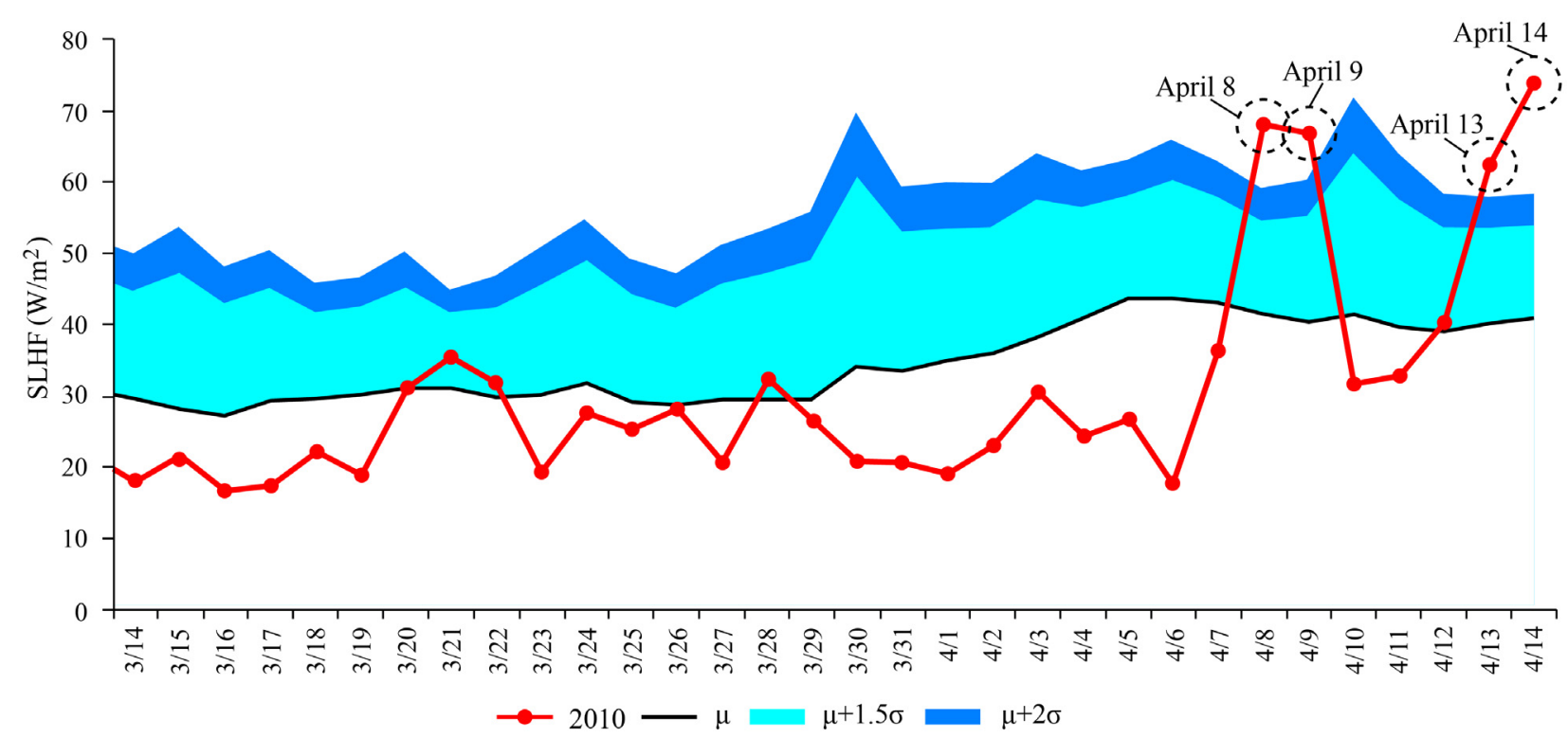

Figure 6. Time series of SLHF data on the epicenter pixel from March 14 to April 14 2010, and its comparison with historical data over the same period. The red line is the SLHF variation curve of 2010, the black line is the mean $(\mu)$ variation curve on the same day during the nonshock years (1979-2009), the cyan and blue zone is the multi-year mean value plus 1.5 times and twice the standard deviation $(\sigma)$, and the arrows indicate the earthquake time. 
judge that the alternative anomalies of SLHF data are on April 8, 9, 13 and 14, respectively, by numerical diagnosis of the time series. This result also consists with $\Delta$ SLH spatial analysis.

Furthermore, the experimental studies on infrared radiation (IR) detection of loaded rock have been confirmed that the lithology affects the spatial-temporal evolution of thermal anomalies. In an IR experiment on the stick-slip of asymmetrical blocks, which found that the IR in the side of harder rock is stronger than in the other side, and the shape of anomalous field is discontinuous and asymmetrical [Wu et al. 2006a]. Actually, lithology at both sides of the Gazi-Yushu fault zone (including F3 and F4 in Figure 4) is very different. In the south side, middle-late Triassic strata distribution is widespread, and the chief sedimentary rocks are shallow marine quartz sandstone and slate. While in the north side, early Devonian eruptive rock masses are formed, such as schist and marble. In addition, the outcrops of ophiolitic melange also disperse in the northern side. This is why the most of anomalous fields of SLHF concentrated within the northern area of the GaziYushu fault zone and showed the fragmentary pattern.

\section{Discussions}

The tectonic earthquake is generally caused by crustal movement in the fault zone, where the acceleration of active fault motion can lead to rock fracture and crustal deformation in lithosphere. Seismicity within the central and eastern Tibet is widespread and the lithosphere beneath Bayan Har Block is in an active period of tectonic movement. During seismogenic process, accumulated stress transforms into the strong energy which finally is released in the form of seismic waves. Hence, no matter what kinds of parameter, the spatial adjacency to the tectonic structure and temporal quasi-synchronism of multiple parameters are extremely significant for earthquake anomaly recognition. For the analysis of correlation between parameter changes and earthquake, DTS (deviation-time-space) criterion was firstly proposed based on Global Earth Observation System of System (GEOSS) [Wu et al. 2012, Qin et al. 2013]. This criterion emphasized that the anomalies are spatially related with the tectonic structure or epicenter, the temporal quasi-synchronism and data deviation with over quantity more than some threshold relative to the normal background values. From the images of SLHF and PSD, the space distribution with high values primarily indicates that the anomalous fields are under the control of active faults or in the vicinity of the epicenter. Moreover, the Guza seismic station is also an ideal position for monitoring seismic activity because in the southeast margin of the Bayan Har Block, where is a critical intersection of NWoriented Xianshuihe fault zone, NE-oriented Longmenshan fault zone and NS-oriented Anning fault zone. According to the results of temporal diagnosis, the alternative anomaly dates of multiple parameters are recognized, and the relative deviation or raw values are given in Table 1. Although the anomalous quantity and time interval of each parameter are not consistent, three parameters obviously have temporal quasi-synchronism between April 8 and April 9 (highlight with bold type in Table 1), 5 to 4 days before the earthquake. April 8 and 9 are reliable dates for SLHF anomalies, and their deviations are $+9.07 \mathrm{~W} / \mathrm{m}^{2}$ and $+6.66 \mathrm{~W} / \mathrm{m}^{2}$ more than twice of standard deviation of the thirty years' data. From the previous researches, the anomalies of PSD at $410 \mathrm{~Hz}$ and radon gas happened at the same day (April 9), and the corresponding values are also higher than the normal level. The spatial patterns and temporal characteristics of these parameters show that the observed anomalies are possibly related to the Yushu earthquake.

The Earth's system consists of multiple, complicated and interactional spheres from the core to the outer space. Once some unexpected disaster events happen, such as earthquake, certain responses will be aroused in other spheres due to the transformation and migration of matters and energy. So, we attempt to interpret a possible comprehensive mechanism of the geo-spheres coupling in the case of Yushu earthquake.

In the lithosphere, active faulting generally results in rock fracturing, crack developing and crust deformation in the Ganzi-Yushu fault zone before the Yushu earthquake. Due to drastic faulting and friction, some underground pore gases (including $\mathrm{Rn}, \mathrm{H}_{2}, \mathrm{CH}_{4}, \mathrm{CO}_{2}$ and $\mathrm{He}$ ) will be extruded from rocks and leak into the surface. Meanwhile, peroxy links in igneous rocks are broken because of lattice dislocation when rocks are

\begin{tabular}{llll}
\hline Parameters & Alternative anomaly date & Days before shocking & Deviation or value \\
\hline SLHF & Apr 8; Apr 9; Apr 13; & $6 \mathrm{~d} ; 5 \mathrm{~d} ; 1 \mathrm{~d} ;$ & $+9.07 ;+6.66 ;+4.35\left(\mathrm{~W} / \mathrm{m}^{2}\right)$ \\
PSDs & Mar 28; Apr 9 & $18 \mathrm{~d} ; 5 \mathrm{~d} ;$ & $10^{-6.5} ; 10^{-6.2}\left(\mathrm{nT}^{2} / \mathrm{Hz}\right)$ \\
Radon & Apr 9; Apr 14 & $5 \mathrm{~d} ; 0 \mathrm{~d} ;$ & $\sim 13.6 ; \sim 21 / 7(\mathrm{~Bq} / \mathrm{L})$ \\
\hline
\end{tabular}

Table 1. Multiple parameters anomaly alternative date and deviation (or value). 
stressed, releasing the positive holes (P-hole) [Freund 2011]. On the regional coversphere, the main soil types are alpine meadow soil and peat soil in the Yushu region. Since loose soil and low vegetation provide the better migration pathway for leaking-out underground gases, the abnormal rise of the radon at Guza seismic station can be accepted theoretically. The effusion of these gases which are emanated from faults and injected to the air near the ground would join in the air ionization process for electronic adsorption with some general gas compositions (including $\mathrm{N}_{2}, \mathrm{O}_{2}$, etc.) together. Then, this process finally generates considerable charged ions and leads to form hydrated ions combining with the water vapor molecules. Meanwhile, water condensation happened in ions hydration process will prompt water phase change and surface energy redis- tribution and further change locally the latent heat transferred from the surface to the atmosphere, resulting in the increment of SLHF. In atmosphere, local air temperature is rising up as a result of the above behaviors, and increscent temperature gradient enhances air flow for heat exchange in atmospheric vertical profile. Moreover, the convective charged ions can be uplifted by the air flow and couple with charge separation. Due to electron density redistribution, it causes local electric field generation and growth. With the local electric field enlarging, anomalous electric signal will propagate to ionosphere under the action of GEC (Global electric Circuit), and finally lead to ionospheric perturbation phenomenon [Pulinets and Davidenko 2014].

Any triggering multiple parameters anomalies is actually caused by regional fracturing and failure in the
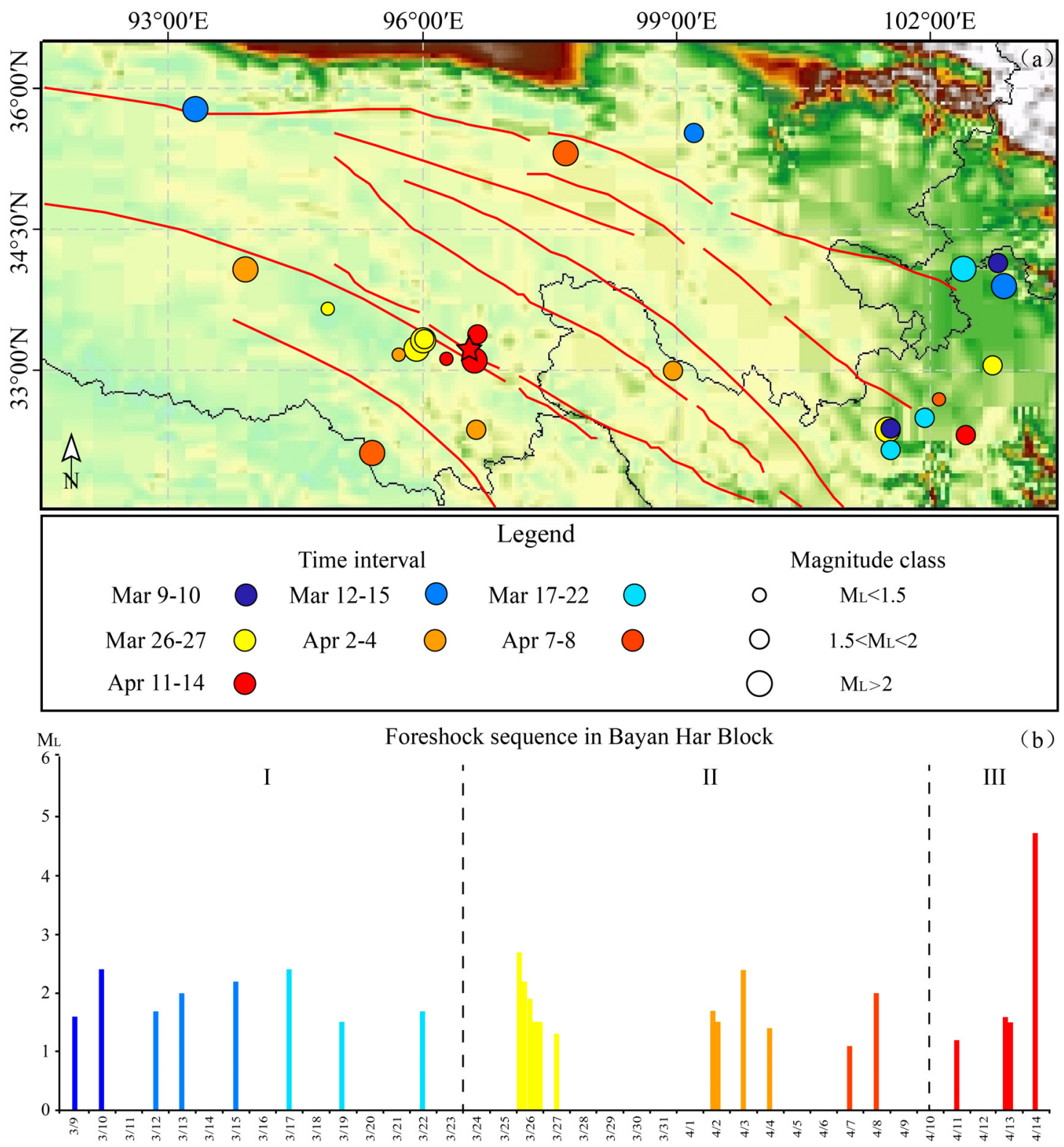

Figure 7. Spatial distribution (a) and temporal sequence (b) of foreshocks in Bayan Har block from March 1 to April 13 (recorded by CENC; http://www. csndmc.ac.cn/newweb/). 
Earth's crust. The time-space evolution of foreshocks is a macroscopic behavior of rock micro-fracturing in lithosphere during the seismogenic process of the Yushu earthquake, more foreshocks intermittently occurred in the block (Figure 7). According to the spatial distribution, the foreshock sequence can be roughly divided into three phases: phase I in northern and eastern margin, phase II in southern and eastern margin and phase III in the vicinity of Yushu epicenter. Coincidentally, the alternative dates of multiple parameters anomalies are at phase II. Pre-shocking microseismic signal has been actually used to investigate earthquake precursor as an important symbol of crustal faulting [De Santis et al. 2010]. Unfortunately, here we cannot discuss microseismic data anomaly further due to data missing. In fact, the spatial distribution of foreshocks implies the stress transfer process and the rock fracturing location in the fault zone before the Yushu earthquake. The experimental studies of remote sensing rock mechanics (RSRM) have proved that infrared radiation (IR) thermal images and acoustic emission (AE) of loaded rock reveal discontinuous and nonlinear variations corresponding to different stress states [Wu et al. 2000, 2006a, 2006b]. When rock fracturing and failure happen in the fault zone, regional matter and energy must change and have similar behaviors with faulting in space and time. Therefore, the result of multiple parameters anomalies can be viewed as a subsequent response of regional fracturing and failure, and they are not only associated with the single Ms7.1 Yushu earthquake, but also with the regional earthquake sequences and tectonic activities in the entire block, even in Tibet. If sufficient foreshock data is available, it can better support the geosystem spheres coupling effect based on the relation between crustal faulting and various observational parameters.

\section{Conclusions}

In this paper, we attempt to examine the possible relationship between ionospheric, radon and thermal anomaly and Yushu earthquake. The results from the reported PSD and radon observation, show that local ionospheric PSD and radon concentration of Guza station enhanced 18-5 days and 5 days before the main shock, respectively. The spatial distribution of PSD anomaly was located around the epicenter except for the anomaly area at conjugate point in the southern hemisphere. And the spot of radon monitoring at the setting of block boundary also has a good ability to reflect underground gas conditions caused by tectonic activity. Meanwhile, our spatio-temporal analysis of SLHF data indicates that local SLHF increased on April 8, 9 and 13, 2010, 6-1 days before the main shock. The anomalous fields of SLHF cover the regional active faults or were close to the epicenter. The temporal quasi-synchronism and spatial anomaly features of these parameters in different spheres could be of precautionary significance. Moreover, their spatio-temporal characteristics can be explained by the IR experimental results of RSRM [38, 40-41]. In conclusion, the case study of Yushu earthquake is contributed to verify the geosystem spheres coupling effect before a single earthquake case and make us deeply understand the coupled spheres response triggered by tectonic activity. It is necessary to mine information of other parameters which could represent physical variations of different spheres in the next work. And we suggest that the anomalies are related with earthquake sequence and tectonic activity in larger scale, not just with single seismogenic fault or a main event. In addition, lithology and land cover of the study area also need to be considered.

Acknowledgements. This work was jointly supported by the National Basic Research Program (973 Program) (Grant No.2011 CB707102) of the China Ministry of Science and Technology, the Fundamental Research Funds for the Central Universities (Grant No.2010YD01).

\section{References}

Chen, L.C., H. Wang, Y.K. Ran, X.Z. Sun, G.W. Su, J. Wang, X.B. Tan, Z.M. Li and X.Q. Zhang (2010). The Ms7.1 Yushu earthquake surface rupture and large historical earthquakes on the Garze-Yushu Fault, Chinese Sci. Bull., 55 (31), 3504-3509.

De Santis, A., G. Cianchini, E. Qamili and A. Frepoli (2010). The 2009 L'Aquila (Central Italy) seismic sequence as a chaotic process, Tectonophysics, 496, 44-52.

Dey, S., and R.P. Singh (2003). Surface latent heat flux as an earthquake precursor, Nat. Hazards Earth Syst. Sci., 3 (6), 749-755.

Freund, F. (2011). Pre-earthquake signals: Underlying physical processes, J. Asian Earth Sci., 41, 383-400.

Fu, B.H., R. Walker and M. Sandiford (2011). The 2008 Wenchuan earthquake and active tectonics of Asia (Editorial), J. Asian Earth Sci., 40, 797-804.

Li, Z.P., J. Cheng and L. Li (2011). Earthquake reflecting ability analysis of the gas radon at Guza seismic station, Journal of disaster prevention and reduction, 27, 14-18 (in Chinese).

Liperovsky, V.A., C.V. Meister, E.V. Liperovskaya, V.F. Dacidov and V.V. Bogdanov (2005). On the possible influence of radon and aerosol injection on the atmosphere and ionosphere before earthquakes, Nat. Hazards Earth Syst. Sci., 5, 783-789.

Liperovsky, V.A., C.V. Meister, E.V. Liperovskaya and V.V. Bogdanov (2008a). On the generation of elec- 
tric field and infrared radiation in aerosol clouds due to radon emanation in the atmosphere before earthquakes, Nat. Hazards Earth Syst. Sci., 8, 1199-1205. Liperovsky, V.A., O.A. Pokhotelov, C.V. Meister and E.V. Liperovskaya (2008b). Physical models of coupling in the lithosphere-atmosphere-ionosphere system before earthquakes, Geomagnetism and Aeronomy, 48 (6), 795-806.

Ouzounov, D., N. Bryant, T. Logan, S. Pulinets and P. Taylor (2006). Satellite thermal IR phenomena associated with some of the major earthquakes in 1999-2003, Phys. Chem. Earth., 31 (4-9), 154-163.

Ouzounov, D., D.F. Liu, C.L. Kang, G. Cervone, M. Kafatos and P. Taylor (2007). Outgoing long wave radiation variability from IR satellite data prior to major earthquakes, Tectonophysics, 431, 211-220.

Pulinets, S.A., K.A. Boyarchuk, V.V. Hegai, V.P. Kim and A.M. Lomonoso (2000). Quasielectrostatic model of atmosphere-thermosphere-ionosphere coupling, Adv. Space Res., 26 (8), 1209-1218.

Pulinets, S.A., D. Ozounov, L. Ciraolo, R. Singh, G. Cervone, A. Leyva, M. Dunajecka, A.V. Karelin, K.A. Boyarchunk and A. Kotsarenko (2006). Thermal, atmospheric and ionospheric anomalies around the time of the Colima M7.8 earthquake of 21 January 2003, Annales Geophysicae, 24, 835-849.

Pulinets, S.A., and M. Dunajecka (2007). Specific variations of air temperature and relative humidity around the time of Michoacan earthquake M8.1 Sept. 19, 1985 as a possible indicator of interaction between tectonic plates, Tectonophysics, 431, 221-230.

Pulinets, S.A., and D. Ozounov (2011). Lithosphere-Atmosphere-Ionosphere Coupling (LAIC) model-an unified concept for earthquake precursors validation, J. Asian Earth Sci., 41, 371-382.

Pulinets, S.A. (2012). Low-latitude atmosphere-ionosphere effects initiated by strong earthquakes preparation process, International Journal of Geophysics, 131842; doi:10.1155/2012/131842.

Pulinets, S.A., and D. Davidenko (2014). Ionospheric precursors of earthquakes and Global Electric Circuit, Adv. Space Res., 53 (5), 709-723.

Qiang, Z.J., X.D. Xu and C.G. Dian (1991). Thermal infrared anomaly precursor of impending earthquakes, Chinese Sci. Bull., 36 (4), 19-323.

Qiang, Z.J., L.C. Kong, M.H. Guo and Y.P. Wang (1995). Laboratory research on mechanism of satellite infrared anomaly, Chinese Sci. Bull., 16, 1403-1404.

Qin, K., G.M. Guo and L.X. Wu (2009). Surface latent heat flux anomalies preceding inland earthquakes in China, Earthquake Science, 22 (5), 555-562.

Qin, K., L.X. Wu, A. De Santis and H. Wang (2011). Surface latent heat flux anomalies before the Ms 7.1
New Zealand earthquake 2010, Chinese Sci. Bull., 56, 3273-3280.

Qin, K., L.X. Wu, A. De Santis, J. Meng, W.Y. Ma and G. Cianchini (2012). Quasi-Synchronous Multiple-Parameter Anomalies Associated with the 2010-2011 New Zealand Earthquake Sequence, Nat. Hazards Earth Syst. Sci., 12, 1059-1072.

Qin, K., L.X. Wu, S. Zheng and S.J. Liu (2013). A Deviation-Time-Space-Thermal (DTS-T) method for Global Earth Observation System of Systems (GEOSS)-based earthquake anomaly recognition: criterions and quantify indices, Remote Sens., 5, 5143-5151.

Rao, G., A.M. Lin, B. Yan, D. Jia, X.J. Wu and Z.K. Ren (2011). Co-seismic Riedel shear structures produced by the 2010 Mw6.9 Yushu earthquake,central Tibetan Plateau, China, Tectonophysics, 507, 86-94.

Saraf, A.K., and S. Choudhury (2004). Satellite detects surface thermal anomalies associated with the Algerian earthquakes of May 2003, Int. J. Remote Sens., 26, 2705-2713.

Shan, B., X. Xiong, Y. Zheng, S.J. Wei, Y.M. Wen, B.K. Jin and C. Ge (2011). The co-seismic Coulomb stress change and expected seismicity rate caused by 14 April $2010 \mathrm{Ms}=7.1 \mathrm{Yushu}$, China, earthquake, Tectonophysics, 510, 345-353.

Singh, R.P., J.S. Kumar, J. Zlotnicki and M. Kafatos (2010). Satellite detection of carbon monoxide emission prior to the Gujarat earthquake of 26 January 2001, Applied Geochemistry, 25, 580-585.

Sun, X.Z., X.W. Xu, L.C. Chen, X.B. Tan, G.W. Su, J. Wang, Z.M. Li and X.Q. Zhang (2010). Characteristics of surface rupture of the Ms7.1 Yushu, Qinghai province earthquake at two representative places, Seismology and Geology, 32 (2), 338-344.

Tadashi, T., and M. Takashi (2009). Experiment and theoretical study of earthquake detection capability by means of microwave passive sensors on a satellite, IEEE Geosci. Remote Sens. Lett., 6 (1), 107-111.

Tronin, A.A. (1996). Satellite thermal survey-a new tool for the study of seismoactive regions, Int. J. Remote Sens., 41 (8), 1439-1455.

Tronin, A.A., M. Hayakawa and O.A. Molchanov (2002). Thermal IR satellite data application for earthquake research in Japan and China, Journal of Geodynamics, 33, 519-534.

Tronin, A.A. (2006). Remote sensing and earthquakes: A review, Phys. Chem. Earth., 31, 138-142.

Wang, S.F., C. Fan, G. Wang and E.C. Wang (2008). Late Cenozoic deformation along the northwestern continuation of the Xianshuihe fault system, Eastern Tibetan Plateau. Geological Society of America, $120(3-4), 312-327$. 
Wang, Y.Z., M. Wang, Z.K. Shen, W.P. Ge, K. Wang, F. Wang and J.B. Sun (2013). Inter-seismic deformation field of the Ganzi-Yushu fault before the $2010 \mathrm{Mw}$ 6.9 Yushu earthquake, Tectonophysics, 584, 138-143.

Wu, L.X., C.Y. Cui, N.G. Geng and J.Z. Wang (2000). Remote sensing rock mechanics (RSRM) and associated experimental studies, Int. J. Rock Mech. Min., 37, 879-888.

Wu, L.X., S.J. Liu, Y.H. Wu and C.Y. Wang (2006a). Precursors for rock fracturing and failure-Part I: IRR images abnormalities, Int. J. Rock Mech. Min., 43, 473-482.

Wu, L.X., S.J. Liu, Y.H. Wu and C.Y. Wang (2006b). Precursors for rock fracturing and failure-Part II: IRR T-Curve abnormalities, Int. J. Rock Mech. Min., 43, 483-493, 2006.

Wu, L.X., K. Qin and S.J. Liu (2012). GEOSS-Based Thermal Parameters Analysis for Earthquake Anomaly Recognition, Proceedings of the IEEE, 100 (10), 2891-2907.

Zhang, X.M., J.D. Qian, X.Y. Ouyang, J.A. Cai, J. Liu, X.H. Shen and S.F. Zhao (2009). Ionospheric electro-magnetic disturbances prior to Yutian 7.2 earthquake in Xinjiang, China, J. Space Sci., 29, 213-221.

Zhao, B.Q., M. Wang, T. Yu, W.X. Wan, J.H. Lei, L.B. Liu and B.Q. Ning (2008). Is an unusual large enhancement of ionospheric electron density linked with the 2008 great Wenchuan earthquake?, J. Geophys. Res., 113, A11304; doi:10.1029/2008JA013613.

Zeren, Z.M., X.H. Shen, X.M. Zhang, J.H. Cao, J.P. Huang, X.Y. Ouyang, J. Liu and B.Q. Lu (2012). Possible ionospheric electromagnetic perturbations induced by the Ms7.1 Yushu earthquake, Earth, Moon, and Planets, 108 (3-4), 231-241.

\footnotetext{
${ }^{\star}$ Corresponding author: Lixin X. Wu, China University of Mining and Technology, School of Environment Science and Spatial Informatics, Xuzhou, China; email: awulixin@263.net. 